\title{
Spectral Behavior of VHF Backscatter From Ionospheric Sporadic E Irregularities in the Equatorial Anomaly Crest Zone
}

\author{
Yen-Hsyang Chu ${ }^{1}$, Shan-Ren Kuo ${ }^{1}$, Chien-Ya Wang ${ }^{2}$ and Hsien-Chien Huang ${ }^{2}$
}

(Manuscript received 28 November 1995, in final form 20 August 1996)

\begin{abstract}
In this article, the spectral behavior of the radar returns from ionospheric irregularities of the sporadic $E$ layer occurring in equatorial anomaly crest zone are investigated using $52 \mathrm{MHz}$ Chung-Li VHF radar. It is shown that the mean Doppler velocity and spectral width for the type 1 radar spectra are within $28 \sim 35 \mathrm{~m} / \mathrm{s}$ and $3 \sim 5 \mathrm{~Hz}$, respectively. Compared with the observational results made with other VHF radars, the Doppler shifts of type 1 spectra obtained here are significantly smaller than those in the equatorial and auroral zones. On the other hand, the mean Doppler velocities of the type 2 radar spectra with the spectral width of $16 \sim 30 \mathrm{~Hz}$ are heightdependent and have values between $-50 \sim 60 \mathrm{~m} / \mathrm{s}$ for the present case. The correlation between the Doppler spectral parameters of the type 2 irregularities, namely, the echo intensity, mean Doppler shift, and the spectral width, are also analyzed in this paper. It is demonstrated that a high correlation exists between echo intensity and spectral width, while a considerably poor correlation prevails between mean Doppler frequency shift and spectral width. These results indicate that the primary mechanism causing the breadth of the Doppler spectrum of type 2 irregularities is the ionospheric electron density fluctuations, not the beam broadening effect. The analysis shows that there is a good correlation between mean Doppler shift of type 2 radar spectra and the slope of echo contour in the range-timeintensity plot, implying that the Es targets responsible for type $\mathbf{2}$ echoes are localized and discrete in the resolution volume. The comparison between the echo intensity of the type 2 radar spectra and foEs and fbEs is also made in this article, where foEs and fbEs scaled from the trace of a $\mathrm{HF}$ ionogram record are the critical frequency and blanket frequency of the sporadic E layer, respectively. This shows that the VHF peak power of the type 2 radar spectra is proportional to the difference between foEs and fbEs. A detailed discussion on this feature is given in the text.
\end{abstract}

(Key words: Ionospheric sporadic E layer, Electron density irregularities, Type 1 echoes, Type 2 echoes, Gradient drift instability)

\footnotetext{
1 Institute of Space Science/Center for Space and Remote Sensing Research, National Central University, Chung-Li, Taiwan, R.O.C.

2 Department of Physics, Chinese Culture University, Taipei, Taiwan, R.O.C.
} 


\section{INTRODUCTION}

For many years, several scientific workers have used radars operating at $20 \mathrm{MHz}$ or above to observe sporadic E irregularities (e.g., Miller and Smith, 1978; Ecklund et al., 1981; Tanaka and Venkateswaran, 1982a, 1982b; Riggin et al., 1986; Moorcraft and Schlegel, 1990; Fukao et al., 1991; Yamamoto et al., 1991, 1992). Based on these observations, advanced knowledge of the dynamics and morphology of sporadic $E$ irregularities has been achieved. However, on examination of the geomagnetic locations of the radars in operation used for the observations of ionospheric irregularities, it is found that no radar is located in the region of $0^{\circ} \sim 28^{\circ}$ geomagnetic latitude. It should be noted that this area is just the zone in which the well-known feature of equatorial anomaly occurs. Therefore, in order to improve the understanding of sporadic E irregularities from the global point of view, the observation made by the radar located in the equatorial anomalous zone, such as the Chung-Li VHF radar, seems to be required.

It has been known for years that on the basis of the Doppler spectral characteristics, the VHF coherent radar returns from the ionospheric sporadic $E$ irregularities in equatorial and mid-latitude areas can be categorized into two major groups, namely type 1 and type 2 echoes (e.g., Kelly, 1989). Type 1 echoes are generally associated with extremely narrow spectra (only a few $\mathrm{Hz}$ ) with a mean Doppler shift close to the phase velocity of the ion-acoustic plasma wave (around $360 \mathrm{~m} / \mathrm{s}$ ). On the other hand, the breadths of the type 2 radar spectra are much larger than those of the type 1 spectra, and their mean Doppler shifts are fairly smaller than the ion-acoustic plasma wave speed. The mechanisms responsible for type 1 and type 2 irregularities occurring in the mid-latitude area are different. For a VHF radar at $50 \mathrm{MHz}$, type 1 irregularities are thought to be attributed to linearly unstable 3-meter gradient drift plasma waves generated by extremely sharp electron density gradients associated with sporadic $\mathrm{E}$ layer. However, type 2 irregularities are considered to be due to the gradient drift plasma instability occurring on the bottom side of the sporadic E layer with a sharp electron density gradient. This sort of plasma instability excites large scale primary plasma waves (at the wavelength of several tens of meters) first, and small scale secondary plasma waves are produced subsequently through the effect of non-linear interaction.

On the basis of the observational results of sporadic E (Es) irregularities by using the Chung-Li VHF radar (Chen, 1993), the VHF Es echoes primarily appear in the height range of $100-120 \mathrm{~km}$ and center at the height of around $110 \mathrm{~km}$. The duration of the echoes ranges from about a few minutes to more than 6 hours with a mean duration of about 45 minutes. Generally, the sporadic E irregularities occur in the dark hours. Analysis shows that they appear more frequently in the period of pre-midnight than in the period of post-midnight, which is quite different from the observations made with MU radar. Occasionally, in the season of June and July, very few VHF Es echoes can be detected before sunset. The mean thickness of Es echoes presented in the height-time-intensity plot is about $20 \mathrm{~km}$ with a variance of $7.5 \mathrm{~km}$.

In this article, the observational results of ionospheric field-aligned sporadic $\mathrm{E}$ irregularities made by the Chung-Li VHF radar are presented and discussed. In Section 2, the characteristics of the Chung-Li VHF radar for the ionospheric observation is introduced. In Section 3, the correlation analyses among echo power, mean Doppler shift and spectral width of the type 
2 radar spectra is made. The comparison of the echo intensity of type 2 irregularities with the difference between the critical frequency and blanket frequency of the sporadic E layer scaled from an ionogram trace is also given in this section. The conclusion is given in Section 4, where it is shown that the consecutive plume-like structures associated with positive radial Doppler velocities (i.e., away from antenna) ranging from $30-55 \mathrm{~m} / \mathrm{s}$ are observed. Moreover, through the spectral analysis of radar returns with fine temporal resolution, two types of radar spectra, namely, type 1 and type 2, are found, on some occasions, to appear simultaneously in the same height range. Different from previous observational results (Fejer and Kelley, 1980; Kelley, 1989), the mean Doppler shifts of the type 1 radar spectra observed here are only $32-38 \mathrm{~Hz}$, somewhat smaller than those obtained in other regions. The plausible mechanisms which cause such a small Doppler shift of type 1 spectra will be discussed in the text.

\section{CHUNG-LI VHF RADAR AND ECHO SIGNAL ANALYSIS}

The Chung-Li VHF radar is located on the campus of National Central University of Taiwan (R.O.C.) with geographic and geomagnetic latitudes of $24.9^{\circ} \mathrm{N}$ and $14^{\circ} \mathrm{N}$, respectively. The Chung-Li VHF radar was originally designed as an ST radar. Accordingly, the original antenna beam can only be steered toward zenith and north, east, south and west at $17^{\circ}$ off-zenith angle such that the 3-dimensional wind field and other important features, such as aspect sensitivity, tropopause, wind shear, precipitation, atmospheric stability, stable layer thickness, lightning, gravity wave activity and momentum flux in the troposphere and stratosphere can be observed. In view of the fact that the peak of the equatorial anomaly generally appears in the range of the geomagnetic latitude of $15^{\circ}$ to $20^{\circ}$ (Rishbeth and Garriott, 1969), it is obvious that the Chung-Li VHF radar is just located within the so-called equatorial anomalous crest zone. To the best of the authors' knowledge, this radar seems to be the only VHF radar in operation within the region of ionospheric equatorial anomaly in the world. The capability of ionospheric observation on the Chung-Li VHF radar has been implemented since the spring of 1992. A new antenna array composed of three rectangular subarrays with 4x8 Yagi elements each was constructed just adjacent to the old one. The half power beam width of each antenna subarray is $7.5^{\circ}$ in elevation and $15^{\circ}$ in azimuth direction. The radar beam is pointed toward the geographic northwest by $17^{\circ}$ with a fixed zenith angle of $41^{\circ}$ such that it is able to be perpendicular to the geomagnetic field line at the altitude of $250 \mathrm{~km}$. The very detailed characteristics of the Chung-Li VHF radar for ionospheric observation can be referred to in Chen (1993) but is summarized in Table 1.

Because the Chung-Li VHF radar is adjacent to the Taipei International Airport, the radar returns coming from aircrafts may seriously contaminate the wanted radar echo signals on occasion. Furthermore, except for the type 1 and type 2 echoes from Es irregularities, the meteor trails may also produce sufficiently strong VHF backscatter. In light of the complexity of the observed Doppler spectrum, the identification of the type 1 and type 2 radar spectra can only be done manually. Once they are separated in the Doppler spectral domain, the echo power, mean Doppler frequency shift and spectral width for these two spectra are estimated individually by the least square method, in which the Gaussian curve is employed to best fit the corresponding Doppler spectral component. 
Table 1. The Characteristics of the Chung-Li VHF Radar.

\begin{tabular}{|c|c|}
\hline Location & Chung-Li, Taiwan, Republic of China \\
\hline Coordinate & $\begin{array}{l}\text { Geographic latitude: } 24.9^{\circ} \mathrm{N} \text {; longitude: } 121^{\circ} \mathrm{E} ; \\
\text { Geomagnetic latitude: } 13.3^{\circ} \mathrm{N} \text {; longitude: } 189.3^{\circ} \\
\text { Dip angle: } 35^{\circ} \mathrm{N}\end{array}$ \\
\hline Frequency & $52 \mathrm{MHz}$ (5.77 m radar wavelength) \\
\hline Peak Transmitted Power & $0.18 \mathrm{MW}$ \\
\hline Pulse Length & $1 \sim 999 \mu \mathrm{s}$ \\
\hline Maximum Duty Cycle & $2 \%$ \\
\hline Maximum Nyquest Frequency & $\sim \pm 160 \mathrm{~Hz}$ \\
\hline \multicolumn{2}{|l|}{ Antenna Array } \\
\hline $\begin{array}{l}\text { type } \\
\text { configuration }\end{array}$ & $\begin{array}{l}3 \text { rectangular arrays of Yagi }(4 \times 8) \\
\text { arranged as a triangle with the respective length of } 40 \mathrm{~m} \text {, } \\
80 \mathrm{~m} \text {, and } 92 \mathrm{~m} \text {, and apex toward the southwest by } 17^{\circ}\end{array}$ \\
\hline $\begin{array}{l}\text { HPBW } \\
\text { steerability }\end{array}$ & $\begin{array}{l}7.4^{\circ} \times 15^{\circ} \text { for each module (elliptic beam) } \\
\text { northward with a fixed zenith angle of } 41^{\circ} \text { (normal to geomagnetic } \\
\text { field line at } 250 \mathrm{~km} \text { ) }\end{array}$ \\
\hline total geometric area & $3 \times 800 \mathrm{~m}^{2}$ \\
\hline Receiver Bandwidth & $\begin{array}{l}\text { Matched filter: } 1 \mathrm{MHz}, 0.5 \mathrm{MHz}, 0.25 \mathrm{MHz}, 125 \mathrm{KHz} \text {, } \\
62.5 \mathrm{KHz} \text { and } 23 \mathrm{KHz} \text {. }\end{array}$ \\
\hline Phase Code & $\begin{array}{l}\text { Complementary Code with } 2,4,8,16 \text { elements } \\
\text { Barker Code with } 7,9,11,13 \text { elements }\end{array}$ \\
\hline Effective Probing Range & $\begin{array}{l}2 \sim 25 \mathrm{~km} \text { (Routine ST Observations) } \\
80 \sim 110 \mathrm{~km} \text { (Meteor Trail Observations) } \\
90 \sim 500 \mathrm{~km} \text { (Ionospheric Irregularities Observations) }\end{array}$ \\
\hline
\end{tabular}

In general, the Chung-Li VHF radar parameters employed for the observation of the sporadic $\mathrm{E}$ irregularities are set as follows: a radar peak transmitted power of $55 \mathrm{kw}$, an inter-pulse period of $1.5 \mathrm{~ms}$, a pulse width of $28 \mu \mathrm{s}$ with a 7-bits Barker code (corresponding to range resolution of $600 \mathrm{~m}$ ), a receiver bandwidth of $250 \mathrm{KHz}$ so as to maximize the signal-to-noise ratio, a coherent integration of 2 or 4 times, a radar probing range generally from $124 \mathrm{~km}$ to $160 \mathrm{~km}$, and 60 range gates are set for each experiment. It shpuld be noted that the apex of the radar beam is steered toward $17^{\circ}$ west of the geographic north with a fixed zenith angle of $41^{\circ}$ such that the radar beam can be normal to the geomagnetic field line at the height of $250 \mathrm{~km}$. In view of the field-aligned property (Ecklaund et al., 1981; Moorcraft and Schlegel, 1990), the backscatter of the sporadic E irregularities can only be generated from the direction perpendicular to the field line at the height where irregularities are situated, i.e., around $110 \mathrm{~km}$. Under these conditions, based on the calculation of the International Geomagnetic Field Model 
(IGRF85), the zenith angle which is responsible for the radar returns of $\mathrm{E}$ region irregularities over the Chung-Li VHF radar site are around $38.5^{\circ}$, other than $41^{\circ}$. Therefore, the height range that corresponds to the slant range from $124 \mathrm{~km}$ to $160 \mathrm{~km}$ covers between $97.7 \mathrm{~km}$ and 126.1 $\mathrm{km}$. The 128-points FFT algorithm is usually employed to compute the Doppler spectrum of Es radar echo signals.

\section{OBSERVATIONS AND DISCUSSION}

\subsection{Type 2 Radar Spectra}

Figure 1 a presents the range-time-intensity plot of the radar backscatter from Es irregularities during the period from 02:58:13LT to 03:11:52LT on January 26, 1995. It should be pointed out that the altitude of the first range gate is about $90 \mathrm{~km}$, while the height increment corresponding to each range gate is $0.47 \mathrm{~km}$. The time resolution for each data point is 1.536 seconds. Because it takes time to transmit the received radar echoes from the master computer to the hard disk, the gaps separating the radar data exist in the plot at a constant rate. As indicated, the Es echoes primarily occur in the height range from about $95 \mathrm{~km}$ to $112 \mathrm{~km}$ for this case. It is noteworthy that several intense meteor echoes characterized by short duration (usually less than $0.5 \mathrm{sec}$ ) and random distribution in the height range from $80 \mathrm{~km}$ to $120 \mathrm{~km}$ can be seen in the contour plot. These echoes may complicate the observed Doppler spectra and should be removed in analyzing the normal Es echoes. Figure $1 \mathrm{~b}$ displays the height distribution of the Doppler spectra for the radar returns in the period from 03:03:27LT to 03:06:04LT (i.e., the time point from 200 to 305 ), as presented in Figure la. As shown in the plot, the fairly broad Doppler spectra with breadth ranging from $5 \mathrm{~Hz}$ to $50 \mathrm{~Hz}$ distribute from range gates 12 to 53 , corresponding to the height range from $95.67 \mathrm{~km}$ to $115.05 \mathrm{~km}$. This kind of broad Doppler spectra with a height-varying mean Doppler shift is categorized as type 2 radar spectra. The echo intensity, Mean Doppler shift and spectral width of type 2 echoes can be obtained by using the least square method, in which the Gaussian curve is employed to best fit to the observed type 2 spectrum. In the following, the statistical analyses among these three spectral moments is given so that the mechanism broadening the type 2 radar spectra can be examined.

Figure 2 presents the scatter diagram of the spectral width versus the mean Doppler shift of the type 2 spectra observed on July 15, 1994 from 00:12:47 LT to 05:10:44 LT. It is clear that no correlation between these two spectral parameters can be seen. This indicates that the beam broadening effect, which arises as a result of the irregularities drifting across the relatively broad antenna beam, on the type 2 spectral width is so small that it can be neglected (Chu et al., 1990). It is worth pointing out that basically the Es irregularities are field-aligned. This characteristics implies that the aspect sensitivity of this kind of target is so high that the radar returns can only be observed in the direction of normal to the magnetic field line. This explains why the beam broadening effect is negligible in analyzing the property of the spectral width of the type 2 echoes. Figure 3 is the scatter diagram of signal power (in dB units) versus the spectral width of type 2 radar spectra. Obviously, a good positive correlation between these two spectral parameters is seen from this diagram. This feature arises due to the fact that, 


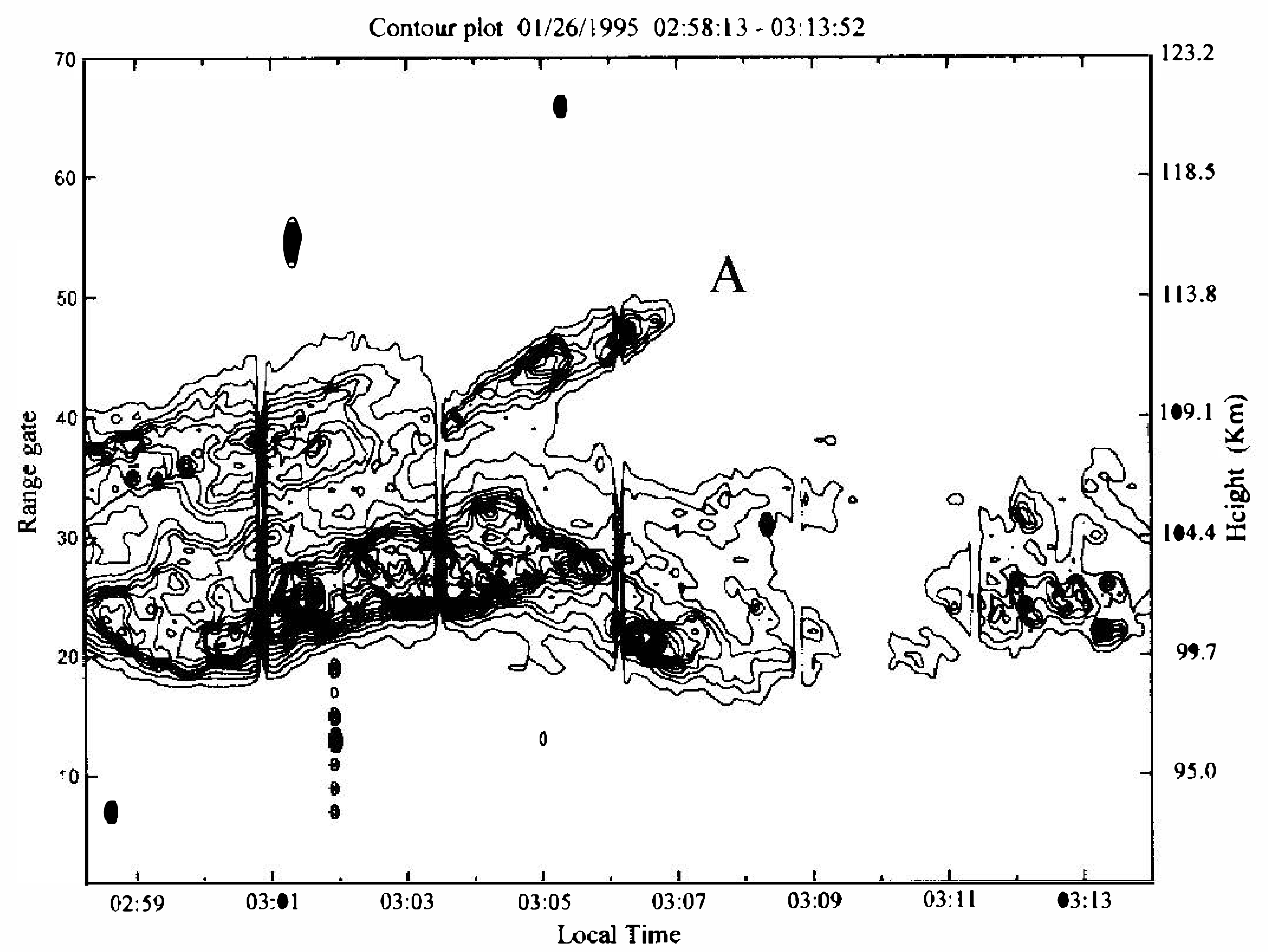

(a)
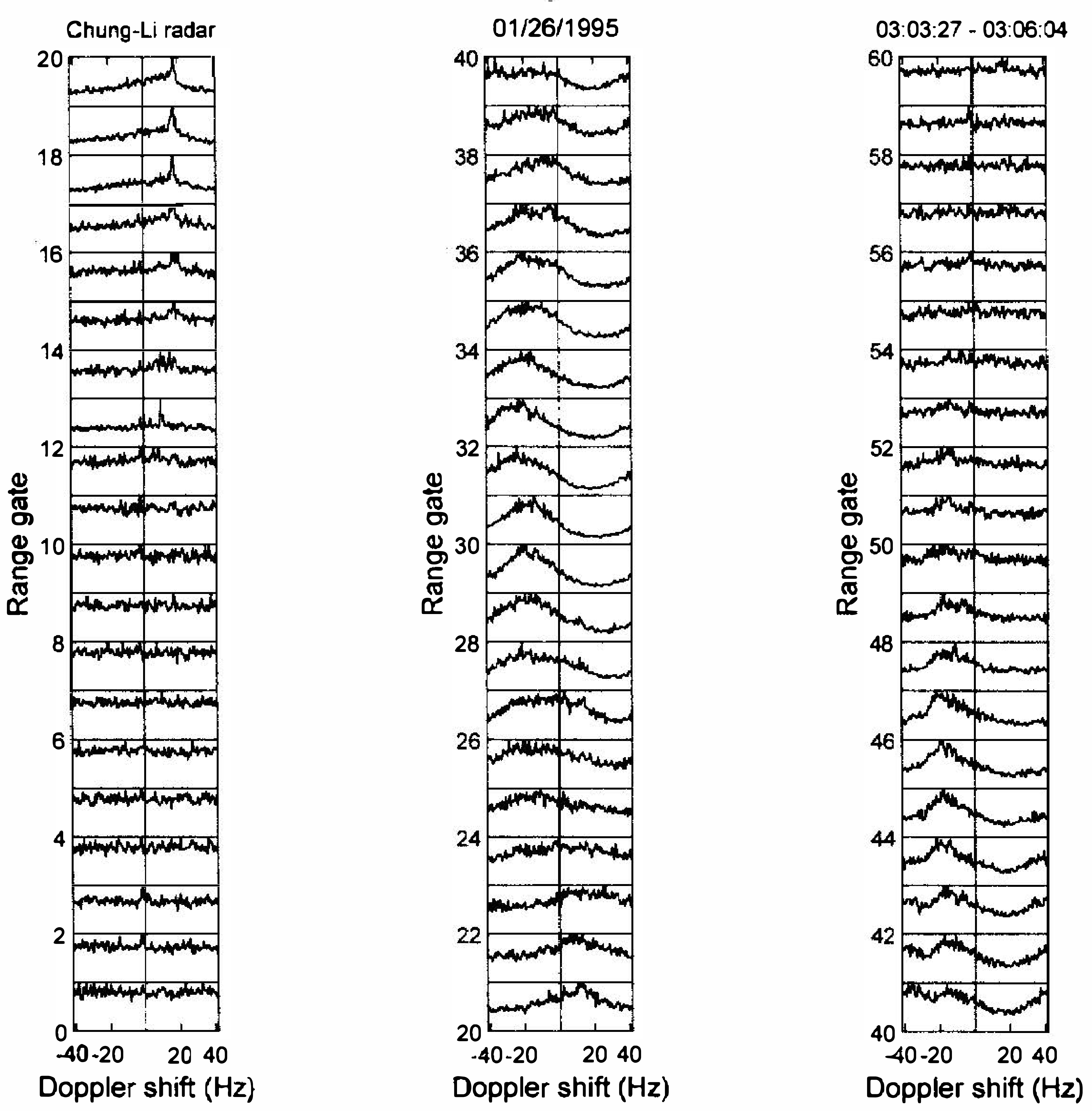

(b)

Fig. 1. (a.) Range-time-intensity plot of the radar backscatter from Es irregularities during the period from 02:58:13LT to 03:11:18LT on January 26, 1995. (b) Height distribution of the Doppler spectra for the radar returns in the period from 03:03:27LT to 03:06:04LT (i.e., the time point from 200 to 305) presented in Figure la. 


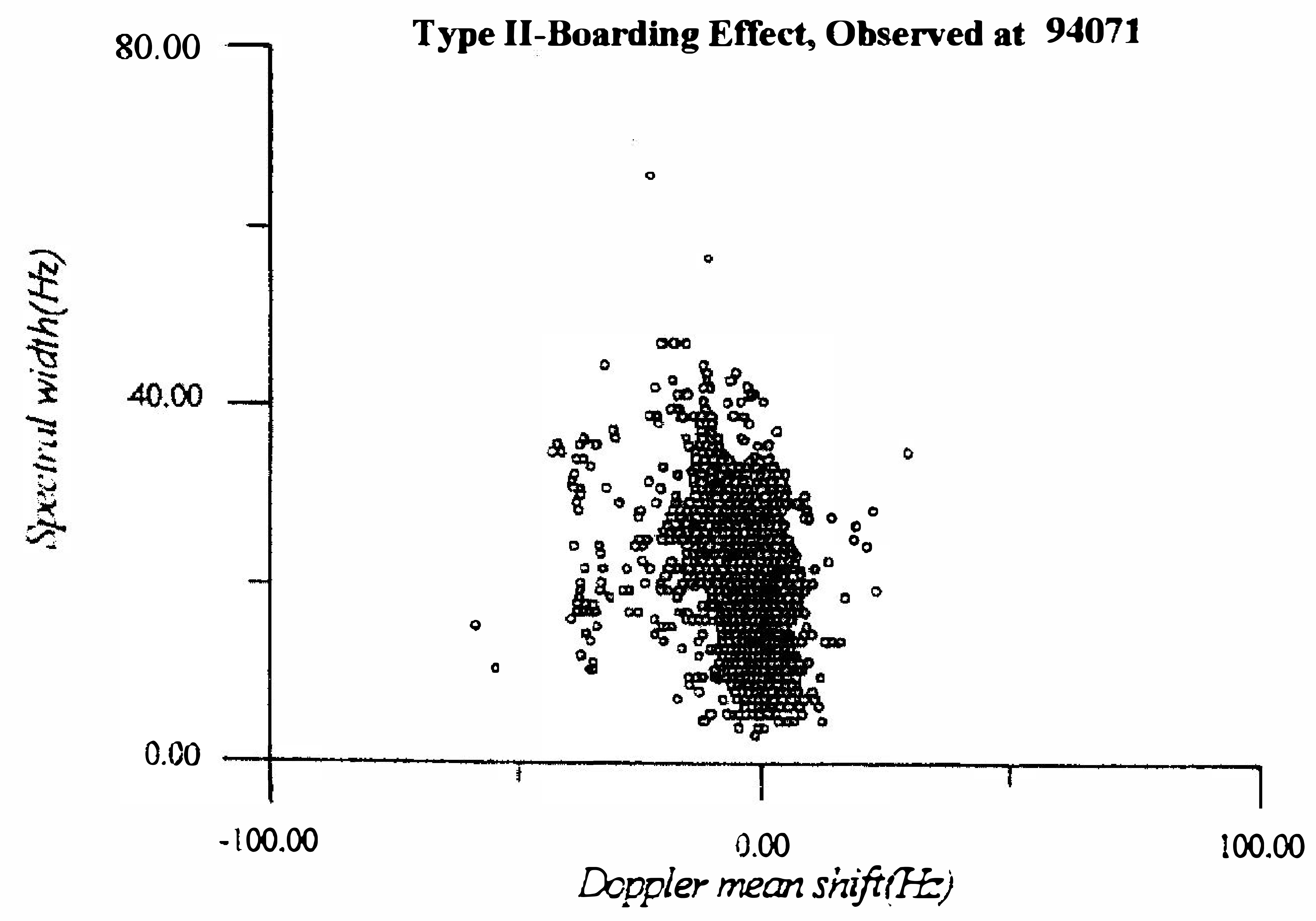

Fig. 2. Scatter diagram of the spectral width versus the mean Doppler shift of type 2 spectra observed on July 15, 1994, from 00:12:47 LT to 05:10:44 LT.

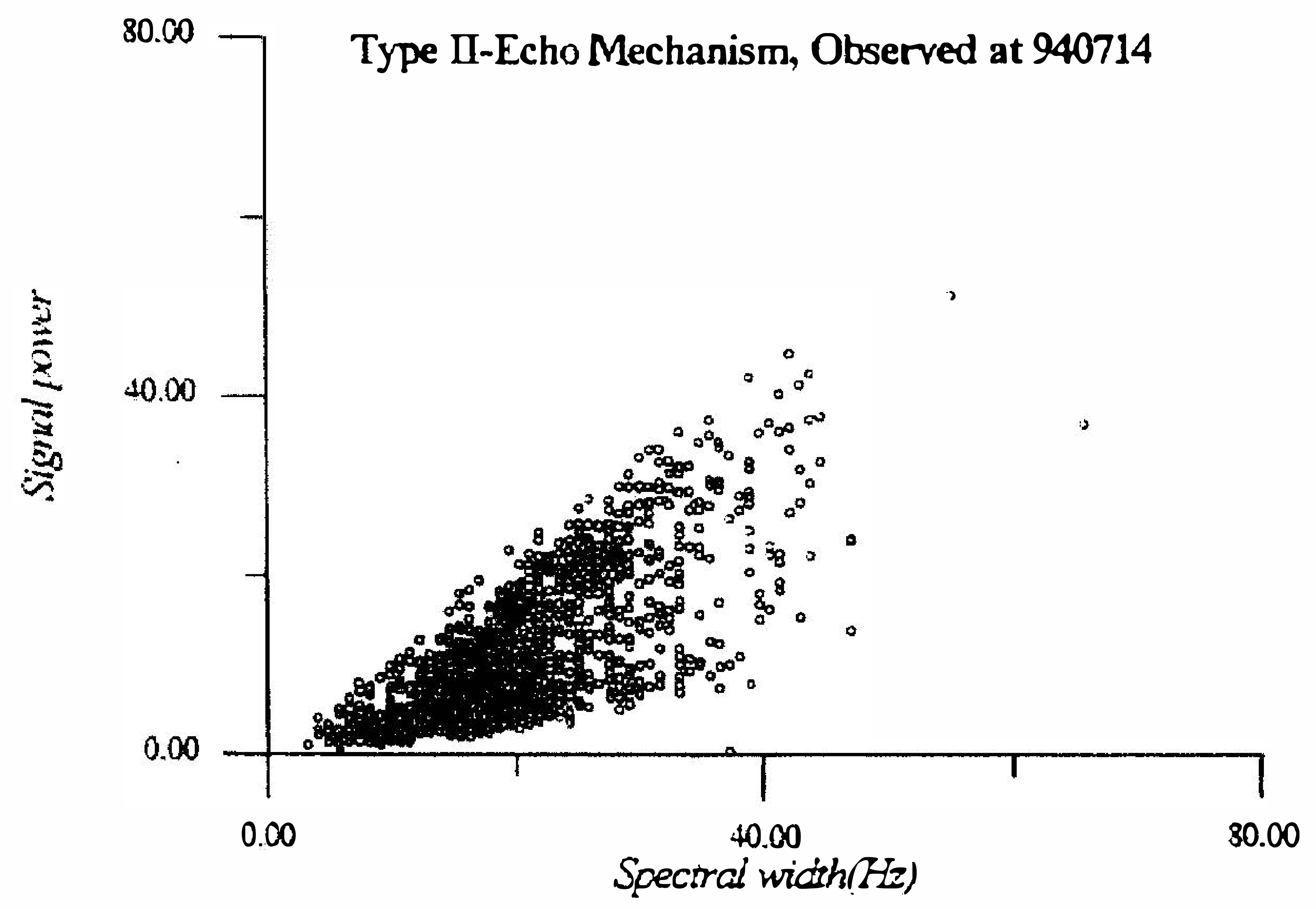

Fig. 3. Scatter diagram of the signal power (in $\mathrm{dB}$ units) versus the spectral width of the type 2 radar spectra. The data used in this plot are identical to those in Figure 2. 
from the scattering theory, the echo intensity of the ionospheric irregularities is proportional to the variance of electron density fluctuations. In addition, as mentioned above, the beam broadening effect plays an insignificant role in contributing to the width of the type 2 radar spectra due to the extreme narrowness of aspect sensitivity. These results suggest that the most important factor in broadening the type 2 radar spectra is the random variations of the ionospheric electron density occurring in the sporadic E layer associated with plasma instability. If the notion as to the formation of the type 2 spectral width is correct, a good correlation between the VHF radar backscatter from Es irregularities, which is closely related to the variance of electron density fluctuations, and the difference between foEs and fbEs scaled from the trace of the sporadic E layer recorded in a conventional HF ionogram is anticipated. This is because, in a general sense, foEs-fbEs represents the large scale variation of the electron density imbedded in the sporadic E layer. Figure 4 presents the scatter diagram of the peak signal-to-noise ratio of the Chung-Li VHF radar returns from type 2 irregularities versus $\Delta$ Es and is defined as:

$$
\Delta E s=\frac{f o E s-f b E s}{f o E s}
$$

where foEs and fbEs are the critical frequency and blanket frequency of the sporadic E layer, respectively, and where both are scaled from the trace of the sporadic E layer in the ionogram obtained by using the Chung-Li HF ionosonde located about $5 \mathrm{~km}$ northwest from the ChungLi VHF radar station. The VHF and HF radar data employed in Figure 4 were taken in the period between April 5 and July 29 of 1992. As shown in Figure 4, it is obvious that the VHF peak signal-to-noise ratio of type 2 irregularities is proportional to the difference between foEs and fbEs. It is noteworthy that the targets embedded in the sporadic E layer responsible for VHF and HF radar returns are quite different. The former are the 3-meter electron density irregularities, while the latter are the dense patches of electron density in the sporadic E layer with the scale of a few hundreds meters. Nevertheless, the common property of these two targets is the inhomogeneity of the electron density. On the basis of the definition of foEs and $\mathrm{fbEs}$, it is evident that the physical meaning of $\Delta \mathrm{Es}$ can be regarded as a measure of the degree of large scale inhomogeneity of the electron density in the sporadic $E$ layer. From the theory of the echo mechanism of VHF radar, it seems clear that the VHF radar echo intensity from type 2 irregularities is proportional to the small scale random fluctuations of electron density associated with plasma turbulence. Since the variations of electron density on the small scale can be generated from those on the large scale through the non-linear plasma turbulent cascade process, it is expected that the $\Delta \mathrm{Es}$ of HF echoes are closely connected to the signal-to-noise ratio of VHF radar returns, as shown in Figure 4.

The detailed examining of Figures $1 \mathrm{a}$ and $1 \mathrm{~b}$ shows that the sign of the mean Doppler shift of type 2 echoes is strongly correlated with the direction of the drift of type 2 irregularities. If the irregularities move upward with time, namely with a positive slope in the rangetime-intensity plot, the mean Doppler shift is negative, and vice versa. Figure 5 shows the scatter diagram of the mean Doppler velocity of type 2 echoes versus the range slope (or rate) 


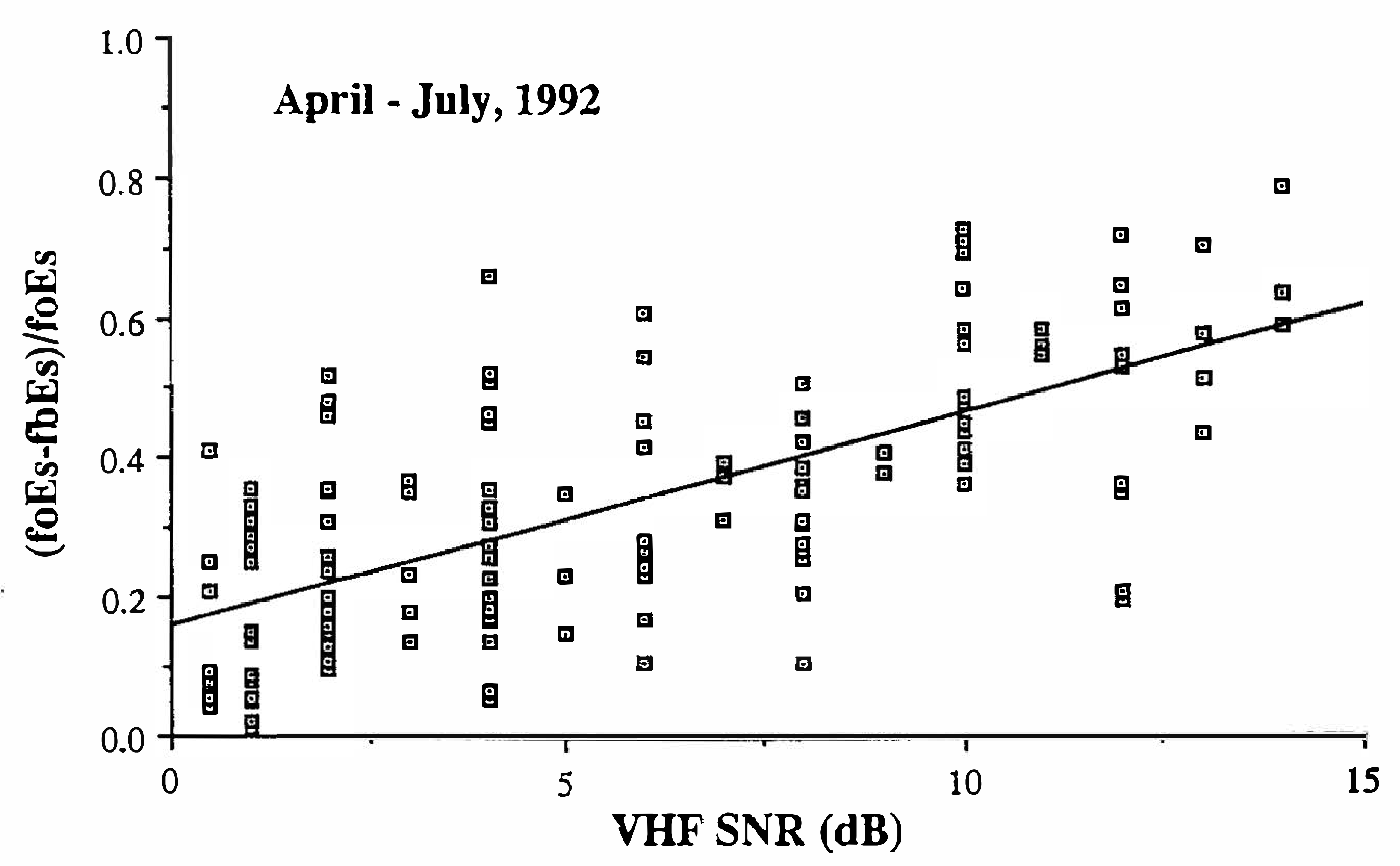

Fig. 4. Comparison of the peak echo intensity of sporadic $E$ irregularities with the parameter $\Delta E s$ which are scaled from Es trace of HF ionogram. The definition of $\Delta E s$ is presented in detail in the text. The data employed in this plot were taken in the period from April 5 to July 29 of 1992.

of the type 2 echoes scaled from the range-time-intensity plot. It is necessary to point out that the radar echoes used for the determination of the range slope are the selected echo patterns with striated structures in the range-time-intensity plot. One example of such echo patterns is presented in Figure la marked with 'A'. The straight line presented in Figure 5 is at the slope of 1. It is clear that the correlation between the range rate and the mean Doppler shift of type 2 echoes is fairly good and the slope of the regression line is less than 1, indicating that the former is slightly larger than the latter. This result implies that this kind of target is responsible for the type 2 echoes localized and distributed inhomogeneously in the resolution volume, a finding which is quite consistent with the field-aligned property of the ionospheric irregularities.

\subsection{Type 1 Radar Spectra}

As mentioned earlier, the radar backscatter from type 1 irregularities are characterized by an extremely narrow spectral width. Usually, type 1 echoes coexist with type 2 echoes in the received radar returns. In fact, it is impossible to distinguish these two echoes in the rangetime-intensity plot. However, it is easy to identify types 1 and 2 echoes in the Doppler spectral domain. Figure 6a presents an example of the contour plot of Es radar returns in which type 1 echoes occur in combination with those of type 2 . Figure $6 \mathrm{~b}$ shows the corresponding Doppler spectral profile in the period from 20:24:29LT to 20:25:46LT. It is clear that in the range gates from 9 to 19, pronounced type 1 spectra with a constant mean Doppler shift of about $10 \mathrm{~Hz}$ and pectra with a mean Doppler shift of $10 \mathrm{~Hz}$ and a spectral width of $20 \mathrm{~Hz}$ are observed. It is to be noted that according to the previous $50 \mathrm{MHz}$ radar observations made in the geomagnetic equatorial and auroral zones (e.g., Kelley, 1989), the mean Doppler shift of type 1 radar 


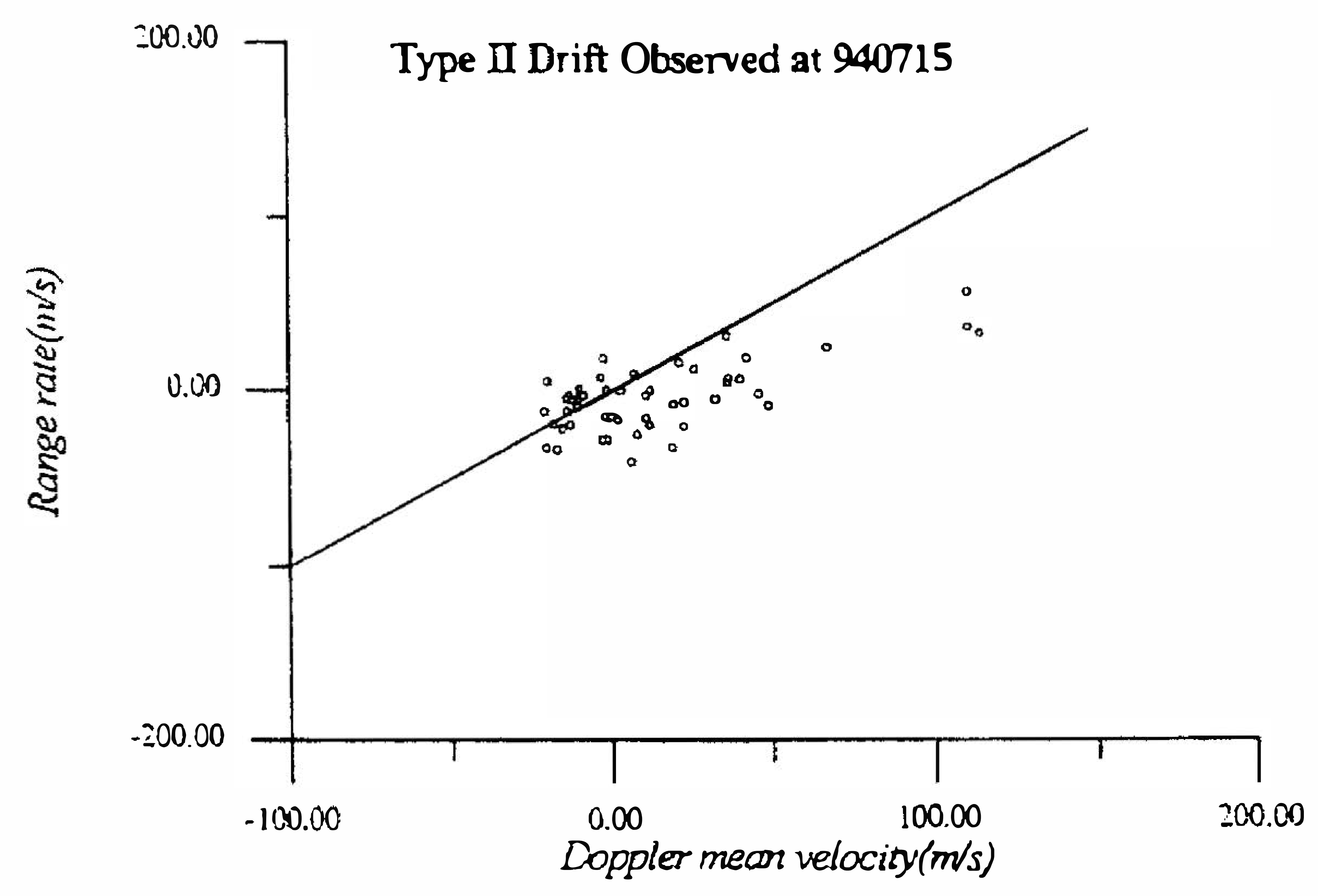

Fig. 5. Scatter diagram of the mean Doppler velocity of type 2 echoes versus the range slope (or rate) of type 2 echoes scaled from the range-time-intensity plot. The radar data used here are the same as in Figures 2 and 3.

spectra for sporadic E irregularities is about $120 \pm 20 \mathrm{~Hz}$ (i.e., corresponding to $360 \pm 60 \mathrm{~m} / \mathrm{s}$ radial velocity) if the ion acoustic wave is responsible for that. By taking the phase speed of the ion acoustic wave and the relative large Nyquist frequency into account, it seems that the aliasing problem on the observed type 1 spectral peak cannot occur. Therefore, it seems that the type 1 radar spectra obtained here may not be explained by using the ion acoustic wave which is responsible for the type 1 spectra observed by $50 \mathrm{MHz}$ radar. However, as reported by Riggin et al. (1986), the averaged Doppler velocity of the type 1 radar spectra observed with $50 \mathrm{MHz}$ CUPRI radar located close to the Arecibo Observatory is about $150 \mathrm{~m} / \mathrm{s}$, which is fairly smaller than the values reported above. In order to explain the enormously small Doppler frequency shift of the type 1 spectra caused by the ion acoustic wave. the conditions of heavy ion mass and the presence of an extremely sharp electron density gradient of the sporadic E layer should both be taken into account. Under these considerations, the threshold velocity of type 1 irregularities could be reached as low as one-fourth (even smaller) of the ion acoustic wave speed (Farley and Fejer, 1975; Riggin et al., 1986). Consequently, the possibility that the type 1 radar spectra shown in Fig.6b is caused by ion acoustic waves cannot be ruled out.

\subsection{Multiple Peaks of Es Radar Spectra}

Based on the experience oh these authors, the feature of multiple spectral peaks of Es radar returns occurs very frequently. The effects causing the bifurcation of observed Es Doppler spectra can be attributed to the interference signals from other radio sources and multitargets coexisting in the scattering volume. The interference signals can be easily identified either in a range-time-intensity plot or in the Doppler spectral domain due to the fact that the 


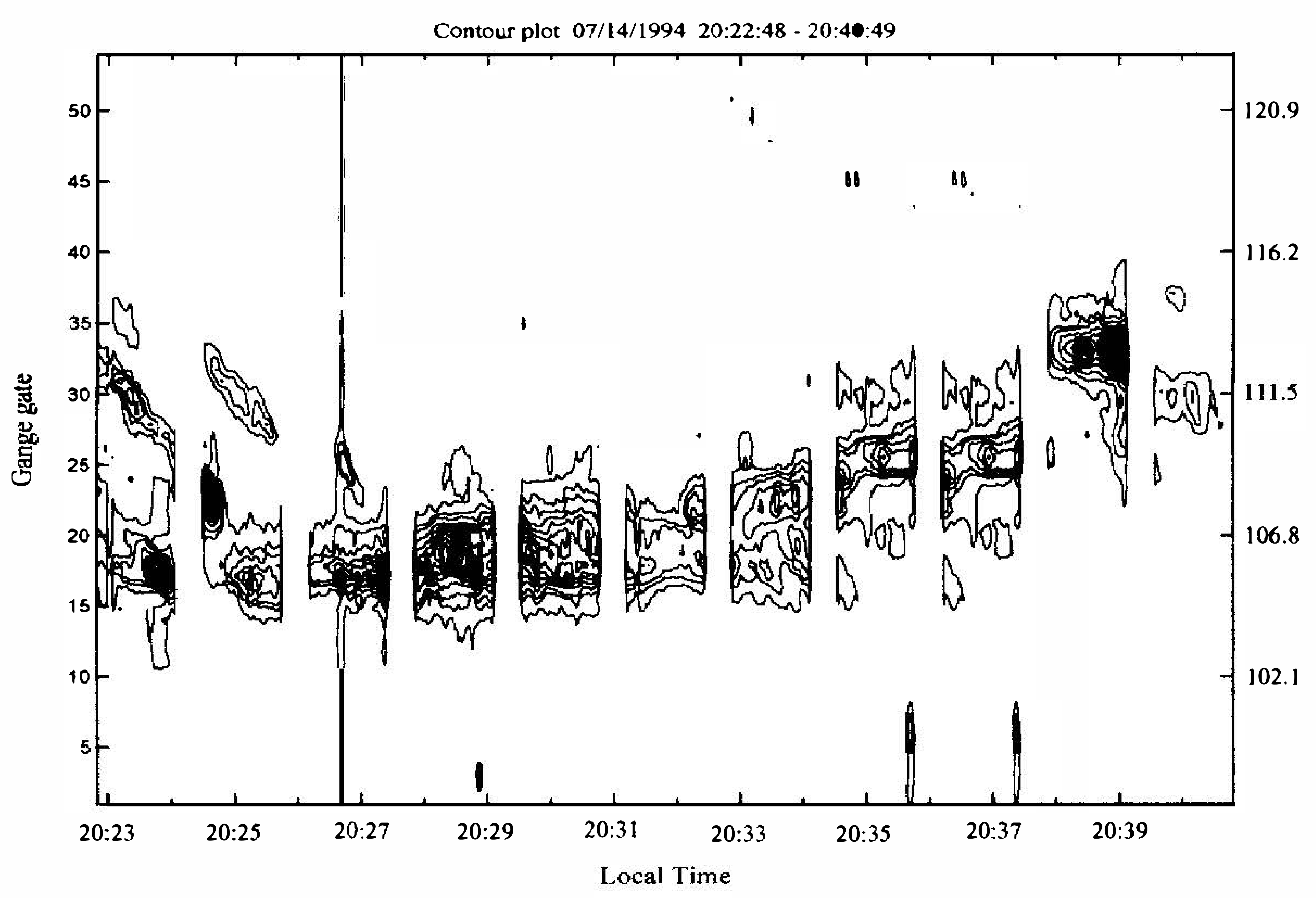

(a)
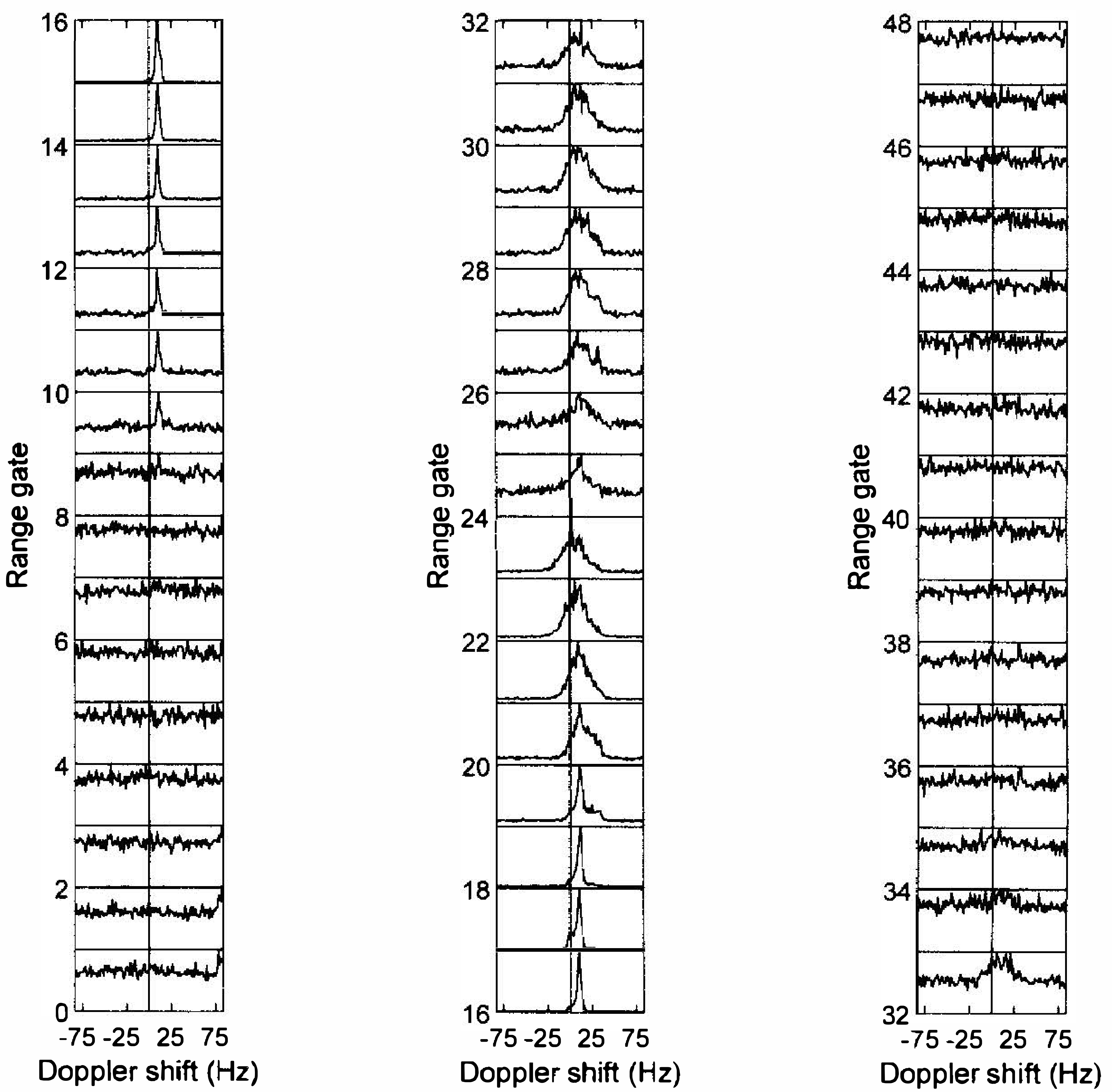

(b)

Fig. 6. (a) Example of a contour plot of Es radar returns in which type 1 echoes occur in combination with type 2 echoes. (b) Doppler spect profile in the period of 20:24:39LT to 20:25:56LT cooresponding to the data presented in Figure 6a. 
y usually appear in the whole range gate and are characterized by a constant Doppler shift with height-independent strength. As for the case of multi-targets in the scattering volume, the echo signal of a meteor trail can be easily distinguished from that of Es irregularities in the rangetime-intensity plot. The observational results (Chu and Chian, 1990; Chu et al., 1995) indicate that the meteor trail echoes are generally short-lived (shorter than $0.5 \mathrm{sec}$ ) and occur in one range gate. In addition, because the 7-bit Barker code was employed in the transmitted pulse waveform, the spurious sidelobe of the decoded radar signals arising from the leakage of the signals at adjacent range gates may appear in the contour plot of the echo intensity, provided that the meteor trail echoes are strong enough. Examples of meteor echoes can be seen in Figure $1 \mathrm{a}$ at the range gates around $8,12,55,67$, and 32, respectively. The spectral shape of the meteor trail echo signal is fairly similar to that of type 1 irregularities. Therefore, the identification of the type 1 radar spectra in the Doppler spectral domain must be treated with some caution. In addition to the meteor trail, if there are two or more localized and discrete ionospheric irregularities with different radial velocities coexisting in the radar volume, the observed Doppler spectrum of the radar returns have double or multiple peaks. In this case, if the respective angular positions of the discrete targets need to be obtained, the radar interferometry technique has to be employed to analyze the radar returns. For more information on this technique, see Kuo (1995).

\section{CONCLUSION}

The capability of the observations of sporadic $E$ irregularities were implemented at the Chung-Li VHF radar in the spring of 1992. This was successful in detecting type 1 and type 2 irregularities in the sporadic E layer. The observational evidence shows that the mean Doppler shift of the type 1 radar spectra is enormously smaller than that observed in the equatorial and auroral regions, indicating that it is necessary to develop a more appropriate plasma instability theory to illustrate the spectral behavior of the ionospheric irregularities occurring in the equatorial anomalous crest region. The average Doppler mean velocity and spectral width of the type 2 radar spectra presented in this article are, in general, between $-50 \mathrm{~m} / \mathrm{s} \sim 60 \mathrm{~m} / \mathrm{s}$ and 16 $\sim 30 \mathrm{~Hz}$, respectively, which is consistent with the observations made by the VHF radars located in other geomagnetic latitudes. The good correlation between spectral width and echo power of type 2 spectra along with the lack of correlation of the mean Doppler shift and the spectral width suggest that the beam broadening effect in contributing to the spectral width of type 2 radar echoes is negligible.

Acknowledgment This study was supported partially by the National Science Council of the Republic of China under the grants NSC85-NSPO-(A)-ECP-())8-01 and NSC85-2612-M034-001.

\section{REFERENCES}

Chen,Y. H., 1993: A study of ionospheric irregularities observed by using the Chung-Li VHF radar, Ph.D dissertation, National Central University (in Chinese).

Chu. Y. H., J. K. Chao, C. H. Liu, and J. Rottger, 1990: Aspect sensitivity at tropospheric 
heights measured with vertically poined beam of the Chung-Li VHF radar. Radio Sci., 25, 539-550.

Chu, Y. H., and T. R. Chian, 1990: The observations of meteor trail made with Chung-Li VHF radar. TAO, 1, 175-192.

Chu, Y. H., Y. M. Chang, Y. Y. Chang, W. J. Chuang, W. W. Lin, and J. S. Song, 1995: The capability of mesospheric observations implemented on Chung-Li VHF radar. Proc. NSC-Part A, 19, 15-14.

Ecklaund,W. L., D. A. Carter, and B. B. Balsley, 1981: Gradient drift irregularities in midlatitude sporadic E. J. Geophys. Res., 86, 858-864.

Farley, D. T., and B. G. Fejer, 1975: The effect of the gradient drift term on the type 1 electrojet irregularities, J. Geophys. Res., 80, 3087-3090.

Fejer, B. G., and M. C. Kelly, 1980: Ionospheric irregularities. Rev. Geophys., 18, 401-430.

Fukao, S., M. C. Kelly, T. Shirakawa, T. Takami, M. Yamamoto, T. Tsuda, and S. Kato, 1991: Turbulent upwelling of the mid-latitude ionosphere 1. Observational results by MU radar. J. Geophys. Res., 96, 3725-3746.

Kelly, M. C., 1989: The earth's ionosphere: Plasma physics and electrodynamics, Academic, San Diego, California.

Kuo, S. R., 1995: The observations of type 1 and type 2 irregularities in the equatorial anomalous crest zone by using Chung-Li VHF radar, National Central University (in Chinese).

Miller, K. L., and L. G. Smith, 1978: Incoherent scatter radar observations of irregular structure in mid-latitude sporadic E layers. J. Geophys. Res., 83, 3761-3775.

Moorcraft, D. R., and K. Schlegel, 1990: Height and aspect sensitivity of large aspect angle coherent backscatter at $933 \mathrm{MHz}$. J. Geophys. Res., 95, 19011-19021.

Riggin, D., W. E. Swartz, J. Prvidakes, and D. T. Farley, 1986: Radar studies of long wavelength waves associated with mid-latitude sporadic layers. J. Geophys. Res., 91, 8011-8022.

Rishbeth, H., and O. K. Garriott, 1969: Introduction to ionospheric physics, Ch.5, Academic Press, New York, $331 \mathrm{pp}$.

Tanaka, T., and S. V. Venkateswaran, 1982a: Characteristics of field-aligned E-region irregularities over Ioka (36 ), Japan, I. J. Atmos. Terr. Phys., 44, 381-394.

Tanaka, T., and S. V. Venkateswaran, 1982b: Characteristics of field-aligned E-region irregularities over Ioka (36 ), Japan, II. J. Atmos. Terr. Phys., 44, 395-404.

Yamamoto, M., S. Fukao, R. F. Woodman, T. Ogawa, T. Tsuda, and S. Kato, 1991: Midlatitude E-region field-aligned irregularities observed with the MU radar. J. Geophys. Res., 96, 15943-15949.

Yamamota, M., S. Fukao, T. Ogawa, T. Tsuda., and S. Kato, 1992: A morphological study on mid-latitude E-region field-aligned irregularities observed with the MU radar. J. Atmos. Terr. Phys., 54, 769-777. 